\title{
LITTÉRATURE
}

\author{
WOJCIECH CHARCHALIS
}

Université Adam Mickiewicz

\section{AL TORNO DE LOS CONCEPTOS DEL REALISMO MÁGICO Y LO REAL MARAVILLOSO - INTENTO DE DIFERENCIACIÓN}

\begin{abstract}
A bstract. Charchalis Wojciech, Al torno de los conceptos del realismo mágico y lo real maravillosointento de diferenciacion [Around the concepts of magic realism and miraculous reality - an attempt at differentiation]. Studia Romanica Posnaniensia, Adam Mickiewicz University Press, Poznań, vol. XXV/XXVI: 2000, pp. 327-335, ISBN 83-232-0965-0, ISSN 0137-2475.

The article presents some notes about the nature of the magic realism that can become useful to formulate a homogeneous definition of the concept. The basic differences between the concepts of magic realism and "lo real maravilloso" of Alejo Carpentier are also exposed. Those terms are frequently erroneously equalled by the critics which generates a terminological confusion that should be cleared. The magic realism is presented as an aesthetic term whereas "lo real maravilloso" is considered as an ontological term, which constitutes the main difference between them.
\end{abstract}

En este artículo vamos a intentar presentar algunos de los rasgos del concepto del realismo mágico, que pueden constituir una base para la formulación de su definición homogénea y compararlos con los rasgos básicos de lo real maravilloso, un concepto frecuentemente confundido o igualado con el realismo mágico.

El término realismo mágico desde su aparición en la tercera década de nuestro siglo sigue siendo mal definido y confuso. Nosotros en este artículo vamos a intentar presentar algunos de los rasgos del dicho concepto, que pueden constituir una base para la formulación de su definición homogénea y compararlos con los rasgos básicos de lo real maravilloso, un concepto frecuentemente confundido o igualado con el realismo mágico.

Al lado del término realismo mágico aparece, a fines de los años cuarenta, uno nuevo, llamado lo real maravilloso, o más bien lo real maravilloso americano. La introducción por Alejo Carpentier a la crítica literaria de este nuevo concepto, en vez 
de ayudar clarificar los procesos que se sucedían en la literatura americana de este periodo, lo complica aun más. Al lado de los términos ya existentes ${ }^{1}$ de realismo mágico y de la literatura fantástica surgió uno nuevo del campo semántico igualmente confuso. Como notó Emir Rodríguez Monegal:

(...) los términos „realismo mágico", „lo real maravilloso americano" y „la literatura fantástica” (...) han sido manejados con cierta irresponsabilidad por la crítica hispanoamericana (...) en vez de permitir la comunicación, la han interrumpido ${ }^{2}$.

Las vagas relaciones entre estos tres conceptos - muchas veces los críticos los confunden o identifican - han causado innumerables discusiones, hasta hoy día, sin llegar a ningún fin satisfactorio. Por ejemplo, José Antonio Bravo en su libro Lo real maravilloso en la narrativa latinoamericana analiza novelas de Alejo Carpentier, Gabriel García Márquez y Juan Rulfo; por otra parte Irlemar Chiampi dedica un capítulo entero para explicar que la fusión de ambos términos en uno denominado „,realismo maravilloso" expresa mejor la naturaleza del problema y no analiza puntos contrarios de los dos conceptos.

Hay que notar que lo real maravilloso y el realismo mágico pueden coexistir dentro de una obra como cualquier otro modo de la representación de la realidad, como es el caso de Cien años de soledad, donde se observa un esfuerzo por parte del autor para buscar los lugares ontológicamente maravillosos, y también acontecen hechos sobrenaturales (por ejemplo el hilo de sangre del muerto José Arcadio que corre por toda la ciudad hasta la cocina para dar a Úrsula la trágica novedad). Esto puede ser la razón por la que muchos críticos confunden los dos conceptos, como es el caso, por ejemplo, del ya mencionado Juan Barroso VIII, quien considera lo real maravilloso como una variante del realismo mágico cuando los temas son propios de América ${ }^{3}$.

Como buen ejemplo de esta confusión de teorías puede servir el XVI Congreso de Instituto Internacional de Literatura Iberoamericana, que tuvo lugar en 1975 donde se abordó la fantasía y el realismo mágico en Iberoamérica. La lectura de las memorias del congreso puede marear al lector con la cantidad de teorías y puntos de vista - el término realismo mágico fue empleado para denominar una extensa gama de fenómenos absolutamente dispares de la literatura latinoamericana. Así, desde la literatura costumbrista e indigenista, hasta la literatura fantástica o puramente imaginaria, surrealista o realista estilísticamente confusa fueron calificadas como mágicorrealistas. Emir Rodríguez Monegal en su artículo Realismo mágico vs. literatura

\footnotetext{
'I. Chiampi, El realismo maravilloso, Monte Ávila, Caracas, 1983 en la página 36 constata que Arturo Uslar Pietri introdujo el término realismo mágico en su artículo Letras y hombres de Venezuela publicado en El Nacional en Caracas un año antes de la publicación, en el mismo periódico, del texto de Carpentier sobre lo real maravilloso, así que con toda razón se puede tomar por sentado de que el cubano lo había conocido.

2 E. Rodríguez Monegal, La narrativa hispanoamericana. Hacia una nueva poética, en Sainz Villanueva, S. y Barbachano, C. J., Teoría de la novela, Madrid, SGEL, 1976, p. 175.

${ }^{3} \mathrm{~J}$. B arroso VIII, „Realismo mágico" y „Lo real maravilloso” en „El reino de este mundo" y „El siglo de las luces", Miami - Florida, Ediciones Universal, 1977, p. 167.
} 
fantástica: un diálogo de sordos hizo una crítica de Ángel Flores y Luis Leal y postuló la sustitución del término realismo mágico por algún otro, mejor definido. Después de este congreso en el mundo crítico reinó cierta tendencia a no emplear dicho término por ser comprometido.

A pesar de gran número de publicaciones sobre el realismo mágico y lo real maravilloso (que para muchos críticos son sinónimos) son escasos los trabajos que intentan definir el fenómeno y presentar la teoría del realismo mágico. Todos hablan del concepto sin definirlo y parece que cada uno de los críticos, hablando, piensa en otra cosa.

Para nuestras reflexiones hemos adoptado la idea de Alfonso Valbuena Briones, según la que el realismo mágico no se limita sólo al continente americano ni tampoco es una forma de expresión propia a los pueblos subdesarrollados como quieren algunos críticos ${ }^{4}$, siendo éste un modo de expresión ,inherente a ser humano"5. También podemos apoyarnos en este momento en el convencimiento de Seymour Menton quien dice:

It is my contention that magic realism is a valid term to describe a tendency found not only in recent Latin American fiction but in the art and literature of Germany, Italy, France, and the United States from the end of World War I to the present ${ }^{6}$.

Vale la pena mencionar que ya Ángel Fores, el primer crítico que intentó definir el concepto ve las raíces del realismo mágico en la Metamorfosis de F. Kafka. Probablemente en cada una de las literaturas nacionales del mundo sería posible encontrar autores cuyos modos de representar el mundo serían parecidos a los autores „clásicos” del realismo mágico americano: G.G. Márquez, M. Á. Asturias etc. En España, un país cuya literatura es tradicionalmente realista, destacan entre otros: G. Torrente Ballester y Álvaro Cunqueiro, autores que crearon sus obras más importantes antes y durante el boom latinoamericano. De los polacos podemos mencionar a A. Majkowski quien publicó su libro Żëcé $i$ przigodë Remusa (en la lengua Kashube), a nuestro parecer mágicorrealista ya en la década de los 30 . Así que la limitación de la expresión mágicorrealista al continente suramericano nos parece injustificada.

De los pocos trabajos que intentan definir el concepto destaca el de Amaryll Beatrice Chanady, donde se proponen tres puntos claves para poder hablar de la existencia

\footnotetext{
${ }^{4}$ Por ejemplo Isabel Allende en una entrevista incluída en el libro de Bautista Gutiérrez, G., Realismo mágico, cosmos latinoamericano. Teoría y práctica, Editorial América Latina, Santafé de Bogotá, D.C., 1991, dice que lo que en la literatura se llama el realismo mágico existe en realidad en los países tercermundistas.

${ }^{5}$ A. Valbuena Briones, Una cala en el realismo mágico, Cuadernos Americanos, 164 (sept.-oct.), 1969, p. 236.

${ }^{6}$ S. Menton, Magic Realism Rediscovered 1918-1981, Philadelphia, The Art Alliance Press, 1983, p. 9.
} 
del realismo mágico. Según la autora norteamericana, para considerar una obra como mágicorrealista, ésta tiene que cumplir las siguientes exigencias:

1) en la obra tienen que existir dos niveles aparentemente contradictorios - el nivel real y sobrenatural;

2) el autor tiene que tratar ambos niveles en el mismo modo, eso es, los dos niveles tienen que coexistir;

3) el autor no se sorprende, no explica ni valoriza nada de lo que pasa en la obra; guarda una posición objetiva en cuanto a la obra?

Se trata de dos niveles que José Antonio Bravo denomina como „realidad objetiva" y ,realidad maravillosa" ${ }^{8}$ las que son aparentemente antónimas - aparentemente porque en el fondo „la realidad objetiva se imprime en la realidad maravillosa” y „ambas forman un todo coherente e indivisible" $"$. Aunque el lector note que los acontecimientos descritos son imposibles en el mundo empírico (en la realidad objetiva), tiene que admitir su existencia en el mundo fictício de la obra. Evidentemente, si lo sobrenatural no es reconocido como tal, no puede existir el realismo mágico ${ }^{10}$. Para un chaman indiano que cree en la existencia de las ánimas en la vida cotidiana, las apariencias de su convivencia con los seres humanos no será maravillosa en ningún modo sino real. Por lo tanto, para la existencia del realismo mágico tiene que existir en la conciencia del lector una delimitación clara de los códigos de lo real e irreal dentro de la obra. La cuestión del lector nos parece extremamente importante tanto en el caso del realismo mágico como en el de lo real maravilloso. El autor mágicorrealista, escribiendo, tiene que tener en cuenta al lector para quien destina sus libros (así llamado por A. B. Chanady „el lector implícito"11). Para crear en el lector los sentimientos previstos el autor tiene que tener una clara idea de su lector, conocer sus supuestas reacciones, ideas, filosofía etc. Como ya hemos mencionado antes, por ejemplo un Indio Maya comprenderá las intervenciones de los seres sobrenaturales en la vida cotidiana de La Mulata de tal de M. Á. Asturias en una manera diferente que un lector occidental.

Los dos siguientes puntos propuestos por A. B. Chanady están implicados por el primero, y en el fondo no hay necesidad de destacarlos como puntos separados. Para que el lector pueda aceptar el mundo de la obra como verdadero, el autor no puede valorizar ninguno de los hechos sobrenaturales. La existencia de lo sobrenatural tiene que ser indiscutible; si el autor explica o justifica lo increíble, ello deja de ser convincente. Si en las calles de Santiago de Compostela de hoy cabalgan los caballeros

${ }^{7}$ A. B. Ch an ady, Magical Realism and the Fantastic. Resolved versus Unresolved Antinomy, Garland, New York \& London, 1985, pp. 21-30.

${ }^{8} \mathrm{~J}$. A. Bravo, Lo real maravilloso en la narrativa latinoamericana actual, 1984, p. 32.

${ }^{9}$ Ibid.

${ }^{10}$ A. B. Chanady, op. cit., p. 22.

" La cuestión del lector implícito fue trabajada por Wayne C. Booth, The Rhetoric of Fiction, The University of Chicago Press, Chicago y Londres, 1961 y Wolfgang Iser, Der Implizite Leser: Kommunikationsformen des Romans von Bunyan bis Beckett, Munich, Wilhelm Fink, 1972. 
medievales - como acontece en Fragmentos de Apocalipsis de G. Torrente Ballester - esto no se debe al cansancio, alucinaciones o al sueño de la persona que los ve. En caso de no cumplir estas dos exigencias los hechos sobrenaturales podrían obtener un significado alegórico o simbólico, lo que también es ajeno al realismo mágico.

El autor mágicorrealista crea mundos ficticios partiendo de una mezcla de personajes, paisajes y acontecimientos históricamente u objetivamente reales. A través de la atribución a estos elementos de unas cualidades sobrenaturales forma un nuevo valor que se llama el realismo mágico. Por ejemplo, cuando G. Torrente Ballester en su Sagalfuga de J.B. describe a Castroforte de Baralla, no tenemos ninguna duda de que se trata de una típica ciudad de la provincia gallega con sus casas, plazas, iglesias y ciudadanos. G. Torrente Ballester mismo llama a este modo de la representación „simbólica" de la realidad ,una realidad suficiente"12 para diferenciar este realismo del realismo del siglo XIX y el del nouveau roman. Sólo cuando la ciudad comienza a levitar - esto es, cuando el autor atribuye a la ciudad real una cualidad sobrenatural - podemos hablar del realismo mágico. En tal situación el lector se sorprende, pero su asombro se desvanece cuando ve que los protagonistas, aunque horrorizados por el descubrimiento, lo aceptan como verdadero y real. La falta de la explicación y crítica por parte del autor o protagonista hace al lector considerar el acontecimiento como aceptable dentro del mundo de la obra.

\section{III}

Alejo Carpentier propuso su concepto de lo real maravilloso como reacción a las creaciones artificiales de los surrealistas. Como todas las imágenes producidas por el arte surrealista tienen caracter accidental, siendo el resultado de asociaciones que tienen lugar en la mente de autor, Carpentier rechaza este tipo de creación y propone uno nuevo, en su totalidad basado en la realidad latinoamericana.

$\mathrm{El}$ autor cubano constata que en toda Hispanoamérica se pueden encontrar lugares que provocan admiración y encanto, lugares maravillosos y mágicos de los que está despojado el viejo continente, donde los artistas buscan los elementos sorprendentes y maravillosos utilizando el subconsciente.

Como dice Juan Barroso VIII:

Los surrealistas para Carpentier se valen de ardides para la creación de lo irreal. Empleando fórmulas y encantamientos que alquilan de las viejas leyendas y crónicas, de la yuxtaposición de los objetos que raramente se encuentran juntos, o de la exageración de rasgos en personajes y escenarios, los

${ }^{12}$ F. H. Blackwell, The Game of Literature. Demithification and Parody in Novels of Gonzalo Torrente Ballester, Albatros Hispanofilia, Valencia, 1985, p. 16. Véase también G. Torrente Ballester, $E l$ Quijote como juego, Destino, Barcelona, 1984; Villanueva, D., El cervantismo de G. Torrente Ballester, Gonzalo Torrenete Ballester: Premio Miguel de Cervantes 1985, Anthropos, 1985 y Ponte Far, J., El Quijote como juego, síntesis de la esencia novelística de GTB, Concepción Arenal: Ciencias y Humanidades, Ferrol, $n^{0} 11,1985$. 
surrealistas crean un mundo irreal. A fuerza de querer maravillar, la sorpresa se hace mecánica, apartándose de lo verdadero y convirtiéndose en artificialidad que invierte la realidad por el escondido propósito de sorprender y el advertido interés de rechazar lo que hasta entonces es aceptado como real $^{13}$.

Según Carpentier, la realidad latinoamericana (con toda su riqueza de las culturas indígenas, negras y europeas, mitos y naturaleza) es maravillosa en sí. La tarea del artista consiste sólo en grabar lo que ve en la tela o sobre el papel. Así que el elemento básico de lo real maravilloso es la realidad sorprendente, increíble; realidad que causa admiración, realidad ontológicamente maravillosa. Podemos afirmar que, según lo dicho, „lo real maravilloso” en comprensión de su inventor es un cierto tipo de „surrealismo ontológico".

Muchos críticos, como Enrique Anderson-Imbert o González Echeverría, no comparten este punto de vista. Ambos notaron, en la polémica con A. Carpentier, que la realidad americana se hace maravillosa en el proceso de creación artística. Anderson-Imbert, quien no hace diferencia entre los términos de lo real maravilloso y el realismo mágico, subraya que empleando el término realismo mágico ${ }^{14} \mathrm{el}$ autor se refiere a la literatura americana y no a su realidad. González Echeverría es aún más concreto:

Suponer que lo maravilloso existe en América es adoptar una (falsa) perspectiva europea, porque sólo desde otra perspectiva podemos descubrir la alteridad, la diferencia - lo mismo visto desde dentro es homogéneo, liso, sin aristas, sin diferencias ${ }^{15}$.

Así que Carpentier, siendo uno de los creadores eminentes de la expresión tipicamente latinoamericana, un escritor que intenta expresar lo americano con toda la riqueza de la herencia de la América precolombina, con toda su flora y fauna es, paradójicamente, un escritor muy occidental. En cuanto, por ejemplo, M. Á. Asturias intenta demostrar, lo maravilloso del Nuevo Continente desde dentro, desde el punto de vista del Indio; A. Carpentier propone una perspectiva lejana, intenta describir América desde la perspectiva de la cultura occidental, escribe para el lector europeo o estadounidense. Para un Indio que toda su vida ha vivido en la selva, las revelaciones del escritor cubano no tendrán nada de maravilloso, serán cosas absolutamente cotidianas. A. Carpentier adopta la perspectiva europea, o más bien occidental, porque sólo en este modo puede llegar a la conclusión de que América es ontológicamente maravillosa.

José Antonio Bravo ${ }^{16}$ propone tres puntos claves de lo real maravilloso que distingue en el Prólogo a El reino de este mundo:

1. Paisaje: geografía, lugares, ambientes exteriores e interiores extraños, misteriosos, remotos, extraordinarios, exagerados.

\footnotetext{
${ }^{13}$ J. B arroso VIII, op. cit., pp. 51-52.

${ }_{14}^{14}$ Carpentier no emplea este término sino lo real maravilloso.

${ }^{15}$ Citado de E. Anderson-Imbert, El realismo mágico y otros ensayos, Monte Ávila Editores, Caracas, 1976, p. 39

16 J. A. Bravo, op. cit.
} 


\section{Personajes: \\ - con atributos superiores \\ - que realizan hechos extraordinarios \\ - en los cuales los que los observan creen, tienen $\mathrm{fe}^{17}$ \\ 3. Los hechos extraordinarios: como fruto de fe de los personajes.}

\section{IV}

Como vemos, estos puntos no son claves para el realismo mágico, o mejor dicho no son sine qua non para la existencia de dicho concepto. El realismo mágico, al contrario a lo real maravilloso, es un término estético y no ontológico, lo que forma la diferencia principal entre los dos conceptos. Por una parte, en lo real maravilloso el autor busca en la realidad objetiva elementos increíbles, sorprendentes que parecen absolutamente improbables para el lector implícito; por la otra, el realismo mágico es una forma de representar la realidad con el empleo de los elementos sobrenaturales que tienen función de un mero recurso estético. En consecuencia, estos elementos parecen admisibles en el contexto de la realidad increíble en el mundo real de la obra. Así que, el mecanismo del funcionamiento de los dos recursos es completamente opuesto. Lo real maravilloso según la definición de A. Carpentier se basa en un convencimento de que la realidad es ontológicamente maravillosa, o en otras palabras, lo real maravilloso es surrealismo que se puede encontrar en la realidad de América Latina ${ }^{18}$. Por lo tanto, las obras creadas según el programa presentado en el Prólogo a $E l$ reino de este mundo son obras realistas ${ }^{19}$, donde el autor busca en la realidad empírica paisajes y acontecimentos sorprendentes, maravillosos. El programa literario de A. Carpentier esta desprendido de elementos sobrenaturales, todos los hechos sobrenaturales que aparecen en sus obras, tarde o temprano tienen que encontrar su explicación racional. Para el realismo mágico no tiene que existir la realidad ontológicamente mágica, surrealista o maravillosa, sino que los hechos maravillosos (creados, inventados por el autor) se situan en la realidad absolutamente objetiva. Por eso,

${ }^{17}$ Tanto Carpentier, como críticos de su obra subrayan la importancia de fe de los personajes, fe en alguien y sus atributos superiores, fe en magia, fe en milagros (alteraciones de la realidad).

${ }^{18}$ André Bretón a la pregunta si existe un México surrealista responde: „México tiende de ser el lugar surrealista por excelencia. Encuentro México surrealista en su relieve, en su flora, en el dinamismo que le confiere - la mezcla de sus razas, así como en sus aspiraciones más altas" - citado de Sánchez Napoleón, N., Lo real maravilloso americano o la americanización del surrealismo, Cuadernos Americanos, 4, vol. CCXIX, VII-VIII 1978, p. 79.

${ }^{19}$ Entrando en el campo de la literatura española el mismo punto de vista encontramos en A. Tarrio Varela, quien considera la prosa de Álvaro Cunqueiro por realista, opinando que los elementos fantásticos de este escritor forman parte de la realidad gallega. Tarrio Varela, A., Realidad y fantasía en la narrativa de Álvaro Cunquiero, in: El relato fantástico en España e Hispanoamérica, ed. Marillas Ventura, E., Madrid, Quintocentenario, 1991. 
podemos decir que el realismo mágico es una mezcla de lo real con lo sobrenatural (o más bien con lo imaginario y fictício).

En el realismo mágico aparecen hechos extraordinarios que en la realidad objetiva son calificados como improbables o imaginarios, pero admisibles dentro del código establecido del mundo literario de la obra. La realidad del mundo mágicorrealista (mundo literario) tiene que ser real para el lector implícito, para que los hechos extraordinarios, improbables en la realidad empírica, puedan ser percebidos como probables dentro del código de la obra. En caso de lo real maravilloso el autor busca realidades - paisajes, vidas, personajes - sorprendentes, improbables, admirables en sí. Como para Carpentier lo real maravilloso es una forma de expresión proporcionada para toda América Latina, los autores de esta poética buscan en la realidad empírica lo típicamente americano que al mismo tiempo forma (para lectores europeos o europeizados) maravillas iguales a los de los surrealistas - con la diferencia de que no son imaginarias sino objetivamente reales. Como dice Enrique Anderson-Imbert: „(...) En esta clase de narraciones los sucesos, siendo reales, producen la ilusión de irrealidad"20. Así que no se puede buscar otra salida sino concordar con el punto de vista de Aléxis Márquez Rodríguez, que ve la base de lo real maravilloso en el sincretismo cultural de América ${ }^{21}$. Desarollando este punto podemos definir lo real maravilloso como un movimiento limitado sólo al continente americano ${ }^{22}$, donde la realidad representada en la obra afecta al lector occidental como irreal; en cuanto al realismo mágico (volviendo a la frase ya citada de Valbuena Briones), éste forma una corriente universal, inherente a ser humano ${ }^{23}$, donde lo imaginario e improbable en la realidad empírica son percebidos por el lector como absolutamente aceptables o reales dentro del mundo de la obra; no perturban al lector como irreal.

\section{BIBLIOGRAFÍA}

Anderson Imbert, E. (1976), El realismo mágico y otros ensayos, Monte Avila Editores, Caracas.

B arroso VIII, J. (1977), „Realismo mágico" y „Lo real maravilloso" en „El reino de este mundo" y „El siglo de las luces", Miami - Florida, Ediciones Universal, 1977.

B autista Gutiérrez, G. (1991), Realismo mágico, cosmos latinoamericano. Teoría y práctica, Editorial América Latina, Santafé de Bogotá, D.C.

B en-Ur, L. E., El realismo mágico en la crítica hispanoamericana, Journal of Spanish Studies, Winter 1976.

\footnotetext{
${ }^{20}$ E. Anderson-Imbert, op. cit., p. 19.
}

${ }^{21}$ A. Márquez Rodríguez, Lo barroco y lo real maravilloso en la obra de Alejo Carpentier, Siglo XXI Editores, México, 1982, p. 45.

${ }^{22}$ Aunque aparecen en otros continentes obras que nos parecen escritas como según la poética propuesta por A. Carpentier. Como ejemplo podemos citar a cuentos de un joven escritor Mozambicano: Mia Couto, Estórias Abensonhadas, Caminho, Lisboa, 1994.

${ }^{23}$ Véase nota 5. 
B lack well, F.H. (1985), The Game of Literature. Demithification and Parody in Novels of Gonzalo Torrente Ballester, Albatros Hispanofilia, Valencia.

B ravo, J. A. (1984), Lo real maravilloso en la narrativa latinoamericana actual.

Carpentier, A. (1967), El reino de este mundo, (Prólogo). Companía General de Ediciones, México.

Chan ady, A. B. (1985), Magical Realism and the Fantastic. Resolved versus Unresolved Antinomy, Garland, New York-London.

Chi a mpi, I. (1983), El realismo maravilloso, Monte Ávila, Caracas.

Flores, Á., Magic Realism in Spanish American Fiction, Hispania, XXXVIII, mayo 1955.

González Echeverría, R., Isla a su vuelo fugitiva - Carpentier y el realismo mágico, Revista Iberoamericana, vol. 40, $\mathrm{n}^{\circ} 86$, jan.-marzo 1974.

Leal, L., El realismo mágico en la literatura hispanoamericana, Cuadernos Americanos, CLIII, julio-agosto 1967.

Llorena, A. (1997), Realismo mágico y lo real maravilloso: una cuestión de verosimilitud, Hispámerica, Univ. de Las Palmas de Gran Canaria.

Márquez Rodríguez, A. (1982), Lo barroco y lo real maravilloso en la obra de Alejo Carpentier, Siglo XXI Editores, México.

Mena, L. I., Hacia una formulación teórica del realismo mágico, Bulletin Hispanique, LXXVII, $3-4,1975$.

Menton, S. (1983), Magic Realism Rediscovered, 1918-1981, Philadelphia, The Art Alliance Press.

Rodríguez Monegal, E., Alejo Carpentier: lo real maravilloso en "El reino de este mundo", Revista Iberoamericana, 37, 1971.

Roh, F., Realismo mágico: problemas de la pintura europea más reciente de Franz Roh, trad. Francisco Vela, Revista de Occidente, XVI, junio 1927.

Sánchez Ferrer, J. L. (1995), Realismo mágico: génesis de un concepto equívovo, Universidad Autónoma Madrid, - tesis inédita.

Sánchez Napoleón, N., Lo real maraviloso americano o la americanización del surrealismo, Cuadernos Americanos, 4, vol. CCXIX, julio-agosto 1978.

Sta wick a-P irecka, B. (1993), La estética del surrealismo y lo „real-maravilloso” en „El reino de este mundo" de Alejo Carpentier, Poznań Literary Papers, 1, Adam Mickiewicz University Press, Poznań.

Valbuena Briones, A., Una cala en el realismo mágico, Cuadernos Americanos, 164, sept.-oct. 1969.

Volek, E., Realismo mágico: notas sobre su génesis y naturaleza en Alejo Carpentier, Nueva narrativa hispanoamericana, 3, 1973.

- Alejo Carpentier y la narrativa latinoamericana actual (dimensiones de un „relismo mágico"), Cuadernos Hispanoamericanos, 296, febrero 1975. 